\title{
Effects of two intensities of treadmill exercise on neuromuscular recovery after median nerve crush injury in Wistar rats
}

\author{
Marcílio Coelho Ferreira ${ }^{1, *}$, Murilo X. Oliveira', Josiane I. Souza², Renato A. Souza ${ }^{3}$, Thaís P. G. Machado', Ana Paula Santos ${ }^{1}$ \\ 'Postgraduate Program in Rehabilitation and Functional Performance, Department of Physiotherapy, Universidade Federal dos Vales do Jequitinhonha e Mucuri, Diamantina, \\ Minas Gerais, Brazil \\ ${ }^{2}$ Animal Experimentation Center, Department of Physiotherapy, Universidade Federal dos Vales do Jequitinhonha e Mucuri, Diamantina, Minas Gerais, Brazil \\ ${ }^{3}$ Federal Institute of South of Minas Gerais, Campus Muzambinho, Muzambinho, Minas Gerais, Brazil
}

Considering the potential action of exercise on neuroplasticity and the need to adapt protocols to enhance functional recovery after nerve injury, this study evaluated the effects of two intensities of treadmill exercise on nervous and muscular tissues and functional recovery after nerve crush injury. Wistar rats were distributed into sedentary group (SED), and $10 \mathrm{~m} / \mathrm{min}$ (EG10) and $17 \mathrm{~m} / \mathrm{min}$ (EG17) exercise groups. The exercise started one week after the injury. Ten daily sessions were performed with a 2-day interval after the fifth day. The flexor digitorum muscle and two segments of the median nerve were analysed histomorphometrically by light microscopy and computer analysis. Function was evaluated by grasping test, in 3 moments. Approval number: 016/2013. In the proximal segments of the median nerve, the diameter of myelinated fibres and axon, the myelin sheath thickness and the ratio of axon diameter to fibre diameter ( $g$ ratio) were significantly larger $(P<0.05)$ in the EG10. The number of myelinated fibres was lesser in the EG17 than the other groups $(P<0.05)$. No difference in the number of myelinated fibres among groups was observed in the distal segments, but the SED presented significantly larger axon and fibre diameters than those that performed exercise. The EG10 presented greater area and diameter of muscle fibres $(P<0.05)$ and functional improvement observed on the 21 st day after injury $(P<0.05)$ compared with the EG17 and SED. Continuous exercise at $10 \mathrm{~m} / \mathrm{min}$ accentuates nerve regeneration, accelerating functional recovery and preventing muscle atrophy.

Keywords: Nerve regeneration, Treadmill exercise, Crush injury, Median nerve, Grasping test, Flexor digitorum muscle

\section{INTRODUCTION}

Peripheral nerve injury is a substantial clinical problem that has devastating consequences for patients (Panagopoulos et al., 2017; Sullivan et al., 2016) and poses a challenge to rehabilitation teams (Faroni et al., 2015; Faturi et al., 2016). Lesions of the peripheral nerves occur most frequently in the upper extremities, with the ulnar and median nerves being the most often affected (Daneyemez et al., 2005; Kouyoumdjian et al., 2017; Miranda and Torres, 2016; Szyłejko et al., 2015); and compression being the most common mechanism (Taylor et al., 2008). Most daily activities require func- tional hands; therefore, nerve injuries in the upper extremities can cause substantial problems for individuals of all ages (Daneyemez et al., 2005; Miranda and Torres, 2016; Szyłejko et al., 2015).

Nerves can be damaged to varying degrees and by many causes (Daneyemez et al., 2005; Kouyoumdjian et al., 2017). The ultimate goal of peripheral nerve repair is effective recovery of function (Udina et al., 2011b); however, this is almost never complete (Geuna et al., 2016; Gordon and Borschel, 2017). After an injury, a peripheral nerve regenerates spontaneously at a very slow rate, approximately $1 \mathrm{~mm}$ per day, depending on the lesion site (Sulaiman and Gordon, 2013; Sullivan et al., 2016). Moreover, the

\footnotetext{
*Corresponding author: Marcílio Coelho Ferreira (iD) https://orcid.org/0000-0003-0377-678X

Postgraduate Program in Rehabilitation and Functional Performance, Department of Physiotherapy, Universidade Federal dos Vales do Jequitinhonha e Mucuri, Diamantina/Minas Gerais, Brazil

E-mail: marciliocf@gmail.com

Received: March 15, 2019 / Accepted: April 17, 2019
} 
regeneration capacity of the peripheral nervous system (PNS) decreases over time (Boerboom et al., 2017).

Some neurorehabilitation strategies have shown benefits in terms of improved functional recovery after PNS injuries. Treatments using exercise have been increasingly studied due to their positive results in the rehabilitation of PNS injuries and their role in neuroprotection and neuroregeneration (Armada-da-Silva et al., 2013; Cobianchi et al., 2017). Different exercise types, such as resistance training with weight (50 to $250 \mathrm{~g}$ ) attached to the animals' tails (Ilha et al., 2008), swimming exercise (20 to $40 \mathrm{~min}$ ) with a progressive load of up to $10 \%$ body weight (Coradini et al., 2015), passive cycling of the limbs (Udina et al., 2011b) and treadmill exercises (Boeltz et al., 2013; Bonetti et al., 2017; English et al., 2011) have been tested to treat PNS injuries.

Exercise promotes axonal regeneration and functional recovery and may improve sensory-motor coordination and restoration of adequate circuitry at the spinal level (Udina et al., 2011b). Exercise also increases axon elongation (Sabatier et al., 2008), promotes Schwann cell regenerative properties and nerve repair (Gordon and English, 2016), and improves functional muscle recovery after nerve injury (Marqueste et al., 2004). For all these reasons, exercise has been attracting interest as a way of accelerating axonal growth and restoring function. However, the literature has shown conflicting evidence regarding the beneficial and deleterious effects of exercise on peripheral nerve regeneration and muscle reinnervation, possibly due to variations in the type of nerve injury, the sort of exercise realized, the duration and intensity of training and when it is initiated (Armada-da-Silva et al., 2013; Cobianchi et al., 2017; Udina et al., 2011a).

Standard rehabilitative exercise protocols for nerve injury need to be properly defined. The intensity of exercise seems to be a critical parameter for neuroprotection and should be taken into consideration (Cobianchi et al., 2017). The aim of this study was to verify the effects of two intensities of treadmill exercise on median nerve regeneration after crush injury in rats. The histomorphometry of the median nerve and the histomorphometry and functionality of the flexor digitorum muscle were evaluated.

\section{MATERIALS AND METHODS}

\section{Animals}

This research was approved by the Ethics Committee on Animal Use of the Federal University of Jequitinhonha and Mucuri Valleys, protocol number 016/2013. The experiments were performed on 24 female Wistar rats (7 weeks old; approximately $170 \mathrm{~g}$ ). The animals were housed under controlled environmental conditions (temperature $22^{\circ} \mathrm{C} \pm 1{ }^{\circ} \mathrm{C}$ and humidity $40 \%-50 \%$ ) with a $12: 12$ hour light-dark cycle and free access to food (Nuvilab CR1; Nuvital Nutrientes S/A, Paraná, Brazil) and water.

\section{Experimental groups}

The animals were randomly divided into three groups with eight each. In the sedentary group (SED), rats underwent median nerve crush and were not exercised. In exercise group $10 \mathrm{~m} / \mathrm{min}$ (EG10) and exercise group $17 \mathrm{~m} / \mathrm{min}$ (EG17), the rats underwent median nerve crush. Seven days after the injury, the animals performed one hr of continuous treadmill exercise training at velocities of $10 \mathrm{~m} / \mathrm{min}$ and $17 \mathrm{~m} / \mathrm{min}$, respectively, 5 days per week, for 2 weeks.

The animals performed the exercise on a motorized treadmill (Insight EP-131; Ribeirão Preto, Brazil) with 6 individual bays, each measuring approximately $10 \mathrm{~cm}$ in width and $38 \mathrm{~cm}$ in length. The exercises were performed with supervision, and no additional stimuli of any kind were applied during the exercise. The rats underwent one week of adaptation before the nerve crush surgery. They walked daily on the treadmill for 5 days per week at a velocity of $10 \mathrm{~m} / \mathrm{min}$ (EG10) and $17 \mathrm{~m} / \mathrm{min}$ (EG17). The training was performed for $10 \mathrm{~min}$ on the first day, $20 \mathrm{~min}$ on the second day, $30 \mathrm{~min}$ on the third day, $45 \mathrm{~min}$ on the fourth day and 60 min on the fifth day.

\section{Surgical procedures for nerve injury}

For the surgical procedures, the animals were anaesthetized by intraperitoneal injection of ketamine (10\%) and xylazine $(2 \%)(0.1$ mL/100 g - Sespo Ind. Com. Ltda, São Paulo, Brazil). After hair trimming, the right median nerve was exposed $10 \mathrm{~mm}$ above the elbow under aseptic conditions, and a crush injury was induced for 2 min by using a standard haemostatic forceps closed to the second notch (Santos et al., 2012). The location of the crush injury was identified with a point on an adjacent muscle. The skin was closed with 4-0 silk sutures. After surgery, digluconate chlorhexidine (Merthiolate; Gold Lab, São Paulo, Brazil) was applied and the animals were kept in individual cages until they awoke. For the first 3 days, paracetamol $(750 \mathrm{mg} / \mathrm{L})$ was added to the water for pain reduction.

\section{Functional evaluation}

The recovery of median nerve function was assessed by means of the grasping test (Bertelli and Mira, 1995). Briefly, the rats were gently lifted by the tail and allowed to grasp a grid connected to 
an ordinary electronic balance. While grasping the grid, the animal continued to be lifted by the tail with increasing force until it lost its grip. At this precise moment, the value shown by the balance was recorded. Before surgery, the right median nerve function was assessed in all the animals in order to obtain baseline control values (presurgery). The animals were then retested on postoperative day 11 and at the end of the experiment (day 21). The contralateral forepaw was temporarily wrapped with adhesive tape to prevent it from grasping the grid. All the tests were performed by a single, skilled investigator who was blinded to the experimental group to which each animal belonged.

\section{Nerve and muscle histological and morphometric analysis}

Twenty-one days after the injury, the animals were weighed and anaesthetized. The median nerve (proximal segment - site of crush and distal segment - forearm, distal 1/3) and the flexor digitorum muscle were exposed, fixed in situ with $4 \%$ paraformaldehyde and removed.

After removal, the nerves were kept in the same fixative solution for an additional $24 \mathrm{hr}$, postfixed with $2 \% \mathrm{OsO}_{4}$ for $12 \mathrm{hr}$, and processed for paraffin embedding. After careful positioning of the nerve fragments in embedding molds, transverse sections were cut at $5 \mu \mathrm{m}$. The sections were observed and photomicrographed on an optical microscope (Primo Star - ZEISS, Jena, Germany) coupled to an Axiocam ERc 5s camera (ZEISS) and were analysed in the image processing program ImageJ. The area of the fascicles was measured manually, and the number of capillaries was counted. Analysis of minimal diameters of axons and myelinated fibres, myelin sheath thickness and the ratio of axon diameter to fibre diameter (g ratio) were carried out in 30\% of the digitized image of each specimen obtained through the $100 \times$ objective (Santos et al., 2007); this process was conducted in a randomized and blind manner. Transverse sections of the flexor digitorum muscle were obtained after the process of paraffin embedding and were stained with hematoxylin-eosin. The minimal Feret diameter and cross-sectional area of 200 random fibres were analysed (Gigo-Benato et al., 2010; Russo et al., 2008).

\section{Statistical analysis}

The data was analysed by using the software GraphPad Prism, ver. 5.0 (GraphPad Software Inc., San Diego, CA, USA). The normality of all data distributions was checked with the ShapiroWilk test. Normally distributed data was compared by analysis of variance (ANOVA), followed by Tukey test; data without a normal distribution was compared by Kruskal-Wallis test followed by Dunn test. Paired $t$-test was used for the functional results pre and postoperative within the same group. Differences were considered significant at $P<0.05$.
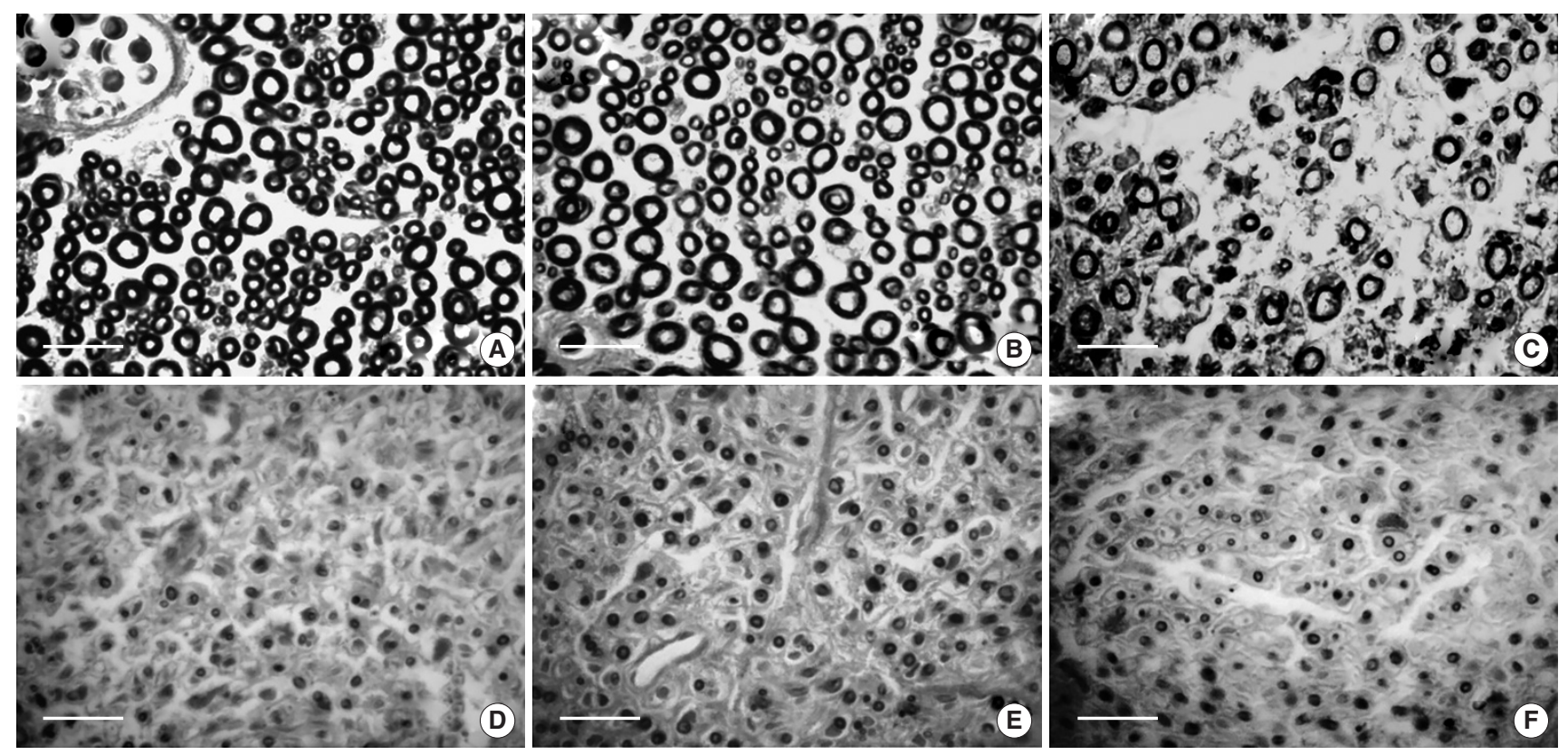

Fig. 1. Digitized images of transverse semi-thin sections of the regenerated median nerve 21 days after nerve crush lesion. The proximal segment (first column) and distal segment (second column) of the median nerve in SED ( $A$ and D), EG10 (B and E), and EG17 (C and F) rats are shown. Magnified by 1,000 times. Scale bars $=20$ $\mu \mathrm{m}$ (A to F). SED, sedentary group; EG10, exercise group $10 \mathrm{~m} / \mathrm{min}$; EG17, exercise group $17 \mathrm{~m} / \mathrm{min}$. 


\section{RESULTS}

Photomicrographs of the proximal (i.e., injury site) and distal segments of the median nerve in the three groups studied are presented in Fig. 1. The proximal segments of the studied groups presented endoneural areas with myelin fibres of various diameters and dispersed capillaries; a morphological similarity between SED and EG10 was observed, while EG17 presented a reduced number of myelin fibres. Small-diameter myelin fibres with enlarged endoneural connective tissue space in the distal segments of the three groups analysed were observed.

The morphometric data obtained from the proximal and distal segments of the median nerve of the three groups is presented in Table 1. In the proximal segments of the median nerve, the myelinated fibres diameter, the axon diameter, the myelin sheath thickness and the $g$ ratio were significantly larger in the EG10 group than in the other groups. The number of myelinated fibres was lesser in the EG17 than the other groups, but was observed an improvement in the diameter of myelin fibres and axons in relation to the SED group. No difference in the number of myelinated fibres among groups was observed in the distal segments, but the SED group presented significantly larger axon and fibre diameters than those that performed exercise. No significant difference in the number of capillaries endoneural was observed between the groups. The values for SED, EG10, and EG17 in the proximal segment were $11 \pm 8,8 \pm 6$, and $6 \pm 1$, respectively; and $10 \pm 8$, $10 \pm 8$, and $7 \pm 5$ in the distal segment, respectively.

The distribution histograms of myelin fibres and axons of the proximal segment of the median nerve presented peak values of 3 $\mu \mathrm{m}$ for myelinated fibre diameter and $2 \mu \mathrm{m}$ for axon diameter. A discrete rightward shift in the EG10 group was observed, but was not repeated in the distal segment. The peaks found in the distal segments were also similar between the groups, from 1.5 to $2 \mu \mathrm{m}$ for the myelin fibre diameter and $1 \mu \mathrm{m}$ for the axon (Fig. 2).

The morphological characteristics of the fibres of the flexor digitorum are shown in Fig. 3. All groups maintained the polygonal shape of the muscle fibres; although, EG10 presented greater calibre of muscle fibres and fewer connective tissue between the cells than the other groups. On the other hand, EG17 presented reduced muscle fibre size and a large number of muscle fibres per image field.

The morphometric data obtained from the flexor digitorum muscle fibres of the three groups is presented in Fig. 4. The EG10 presented greater area and diameter of muscle fibres compared with the SED and EG17 groups $(P<0.05)$.

The results of the functional assessment are reported in Fig. 5. On the 11th day after injury, the groups that performed exercise presented greater muscular strength than the sedentary group. The strength at the 11th day corresponded to 76\% (EG10), 54\% (EG17), and 28\% (SED) of the strength on the preoperative day. A significant difference $(P<0.05)$ between the EG10 compared with the EG17 and SED groups was observed on the 21st day after injury, and the values obtained were 136\%, 94\%, and 109\% of the values on the preoperative day, respectively. EG10 presented better results $(P=0.002)$ on day 21 than preoperative $(295 \pm 48$ $\mathrm{g}$ and $217 \pm 35 \mathrm{~g}$, respectively). On the other hand, no difference between EG17 and SED groups in the preoperative day and 21 postoperative day was found.

\section{DISCUSSION}

Peripheral nerve injury results in severe disability, pain and decreased quality of life (Panagopoulos et al., 2017; Sullivan et al., 2016); therefore, methods that facilitate the process of adequate

Table 1. Morphometric data of the myelinated fibres for proximal and distal segments of the median nerve in the three groups studied

\begin{tabular}{|c|c|c|c|c|c|}
\hline Group & No. of myelinated fibres & Fibre diameter ( $\mu \mathrm{m})$ & Axon diameter ( $\mu \mathrm{m})$ & Thickness of myelin sheath ( $\mu \mathrm{m})$ & g-ratio \\
\hline \multicolumn{6}{|c|}{ Proximal segment } \\
\hline SED & $335.4 \pm 181.7^{\mathrm{a})}$ & $3.64 \pm 1.37$ & $1.88 \pm 0.83$ & $0.87 \pm 0.38$ & $0.51 \pm 0.10$ \\
\hline EG10 & $343.3 \pm 121.8^{\mathrm{a})}$ & $4.17 \pm 1.58^{\mathrm{a}, \mathrm{bl}}$ & $2.25 \pm 1.07^{\mathrm{a}, \mathrm{bl}}$ & $0.96 \pm 0.39^{\mathrm{a}, \mathrm{bl}}$ & $0.53 \pm 0.12^{a, b l}$ \\
\hline EG17 & $131.1 \pm 106.8$ & $3.88 \pm 1.23^{b l}$ & $2.07 \pm 0.96^{b l}$ & $0.90 \pm 0.29$ & $0.52 \pm 0.12$ \\
\hline \multicolumn{6}{|c|}{ Distal segment } \\
\hline SED & $87.5 \pm 57.4$ & $1.99 \pm 0.62^{\mathrm{a})}$ & $1.10 \pm 0.42^{a)}$ & $0.44 \pm 0.14$ & $0.54 \pm 0.08^{\mathrm{a}}$ \\
\hline EG10 & $103.2 \pm 56.3$ & $1.83 \pm 0.37^{b /}$ & $0.99 \pm 0.27^{b)}$ & $0.42 \pm 0.11^{a, b l}$ & $0.53 \pm 0.09^{a)}$ \\
\hline EG17 & $115.9 \pm 38.3$ & $1.88 \pm 0.54$ & $1.00 \pm 0.36$ & $0.44 \pm 0.13$ & $0.52 \pm 0.08$ \\
\hline
\end{tabular}

Values are presented as mean \pm standard deviation, referring to microscopic fields analysed (30\%).

SED, sedentary group; EG10, exercise group $10 \mathrm{~m} / \mathrm{min}$; EG17, exercise group $17 \mathrm{~m} / \mathrm{min}$.

alIndicates a significant difference from the EG17 group. ${ }^{b}$ IIndicates a significant difference from the SED group. Differences were considered significant at $P<0.05$. 

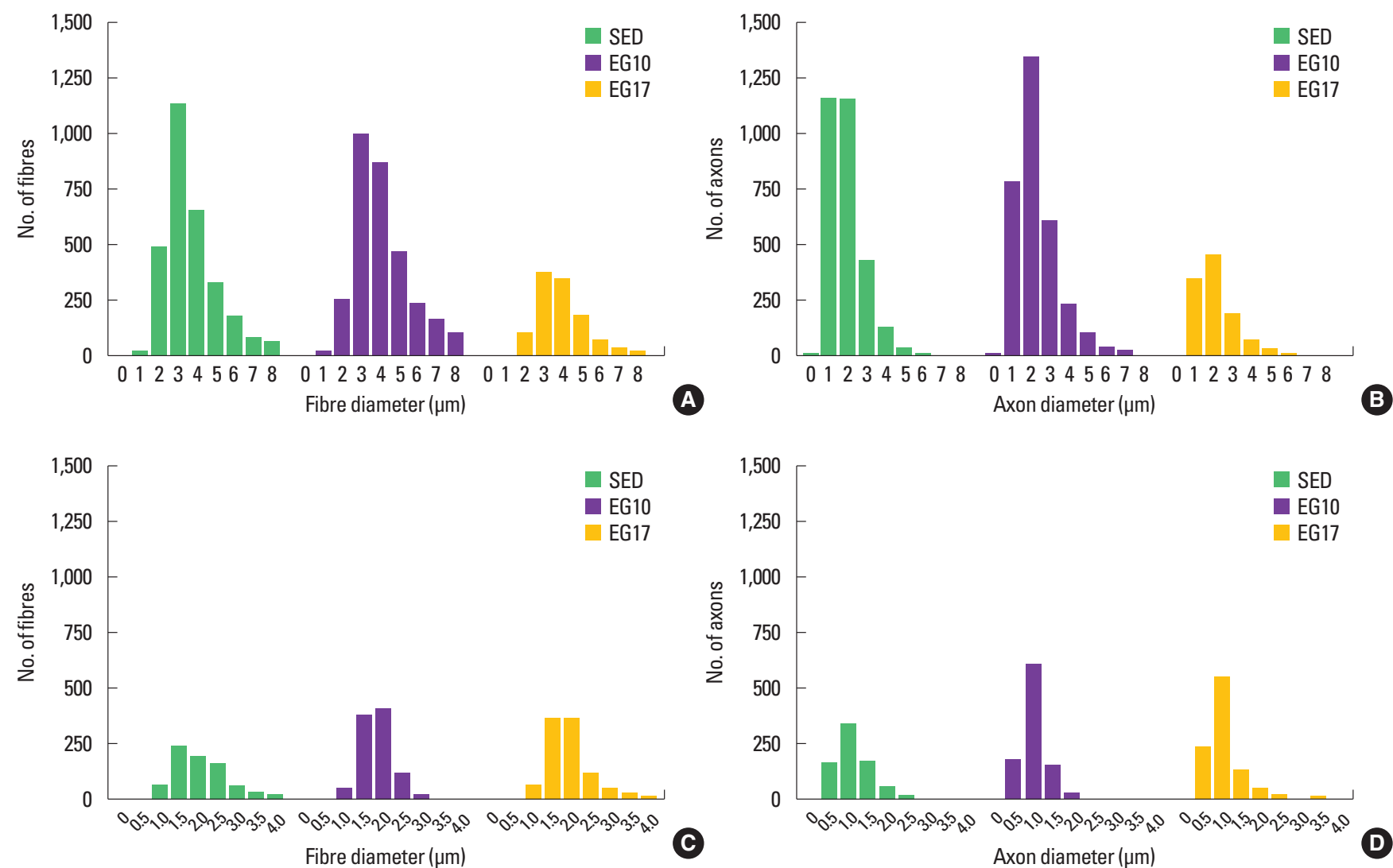

Fig. 2. Histograms showing the distribution of myelinated fibre $(A$ and $C)$ and axon $(B$ and $D)$ diameters for the proximal $(A, B)$ and distal $(C, D)$ segments of the median nerve. SED, sedentary group; EG10, exercise group $10 \mathrm{~m} / \mathrm{min}$; EG17, exercise group $17 \mathrm{~m} / \mathrm{min}$.
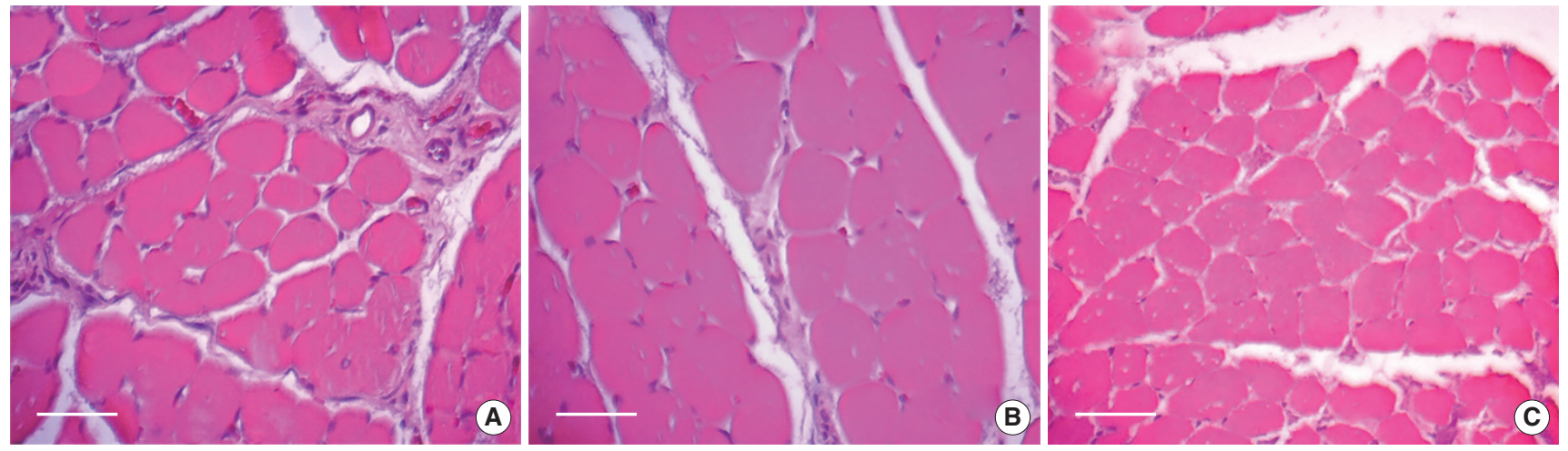

Fig. 3. Digitized images of transverse semi-thin sections of the flexor digitorum muscle on the 21st day after injury. (A) SED. (B) EG10. (C) EG17. Magnified by 400 times. Scale bars $=40 \mu \mathrm{m}$ (A to C). The sections were stained with hematoxylin-eosin. SED, sedentary group; EG10, exercise group $10 \mathrm{~m} / \mathrm{min}$; EG17, exercise group $17 \mathrm{~m} / \mathrm{min}$.

nerve regeneration and functional return, such as therapeutic exercises, are of great relevance. In the upper limbs the distance to the target organs is shorter than in the lower limbs, decreasing the time required for reinnervation and thereby presenting an experimental advantage (Bontioti et al., 2003). Forelimb models have no contracture or autotomy that interferes in functional evaluation
(Bertelli and Mira, 1995; Bontioti et al., 2003). Also, the grasping test is useful since the median nerve and finger flexor function can be easily assessed, furthermore, the grasping test is an objective and reliable method that allows researchers to track recovery progress during the repair process (Bertelli and Mira, 1995; Papalia et al., 2003, 2016; Ronchi et al., 2009). 

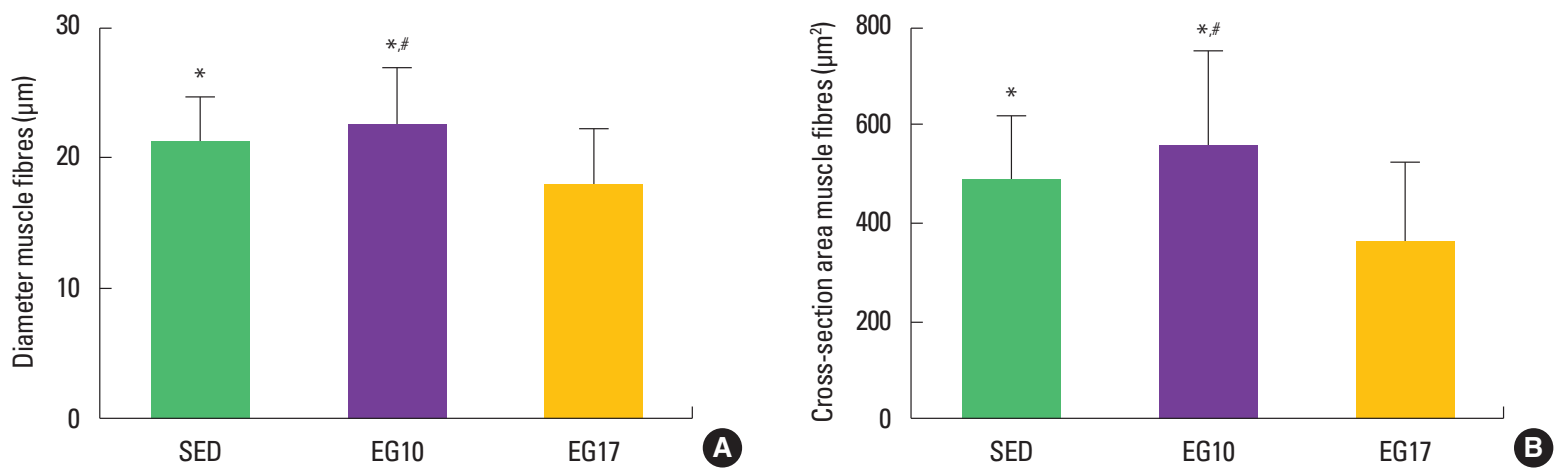

Fig. 4. Mean values of the flexor digitorum muscle. (A) Diameter of the cross section of the muscle fibre. (B) Cross-sectional area of muscle fibre. SED, sedentary group; EG10, exercise group $10 \mathrm{~m} / \mathrm{min}$; EG17, exercise group $17 \mathrm{~m} / \mathrm{min}$. ${ }^{*}$ Differs from EG17 at $P<0.05$. . Differs from SED at $P<0.05$.

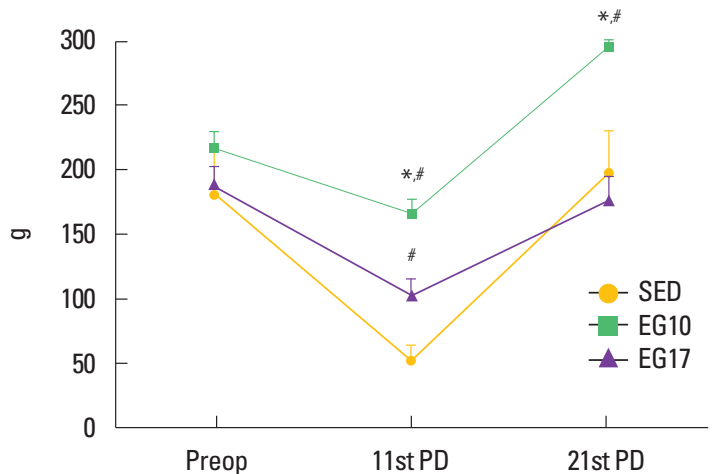

Fig. 5. Comparison of grip strength between the groups. Data is presented as the mean \pm standard error of the mean. Differences were considered significant at $P<0.05$. Preop, preoperative day; $P D$, postoperative day; SED, sedentary group; EG10, exercise group $10 \mathrm{~m} / \mathrm{min}$; EG17, exercise group $17 \mathrm{~m} / \mathrm{min}$. *Indicates a significant difference from EG17. "Indicates a significant difference from SED.

In this study, crush injury of the rat median nerve was used as a model to investigate the hypothesis that two treadmill training intensities would produce different effects on functional recovery and on histological and morphometric aspects of the median nerve and flexor digitorum muscle. Crush lesions are simple, have lower variability in the regeneration response than transections and is a good model for studding motor recovery (Ronchi et al., 2009).

The treadmill training at $10 \mathrm{~m} / \mathrm{min}$ resulted in an improvement in the variables related to the histomorphometry of the flexor digitorum muscle and in the variables related to myelinated fibres proximally to lesion site. No improvement in the variables related to the myelinated fibres was observed in the distal segment of the median nerve, however, the $g$ ratio-a ratio that is relevant to ideal saltatory conduction and useful for assessing nerve diseases (a ratio of approximately 0.6 is ideal) (Gutrecht and Dyck, 1970; Rushton, 1951)—was similar in this segment to that of the sedentary group and more favourable than that of the $17 \mathrm{~m} / \mathrm{min}$ group. Better $\mathrm{g}$ ratio and higher thickness of myelin sheath were also found in the study of Ilha et al. (2008) $5 \mathrm{~mm}$ distal to the crushing site in the trained group (treadmill $9 \mathrm{~m} / \mathrm{min}$ ).

The distributions of the myelinated diameters were unimodal in all groups, as found in the corresponding nerve segments in uninjured animals of the same age (Santos et al., 2007), but with lower peaks. In the proximal segment, the $10 \mathrm{~m} / \mathrm{min}$ group presented the closest distribution to that found in normal control data (Santos et al., 2007).

The angiogenic action of exercise is known (Lansford et al., 2016; Terra et al., 2012); a higher number of vessels could minimize the effects of hypoxia and enhance nerve regeneration (Kakihata et al., 2016). In this study, no difference in the number of endoneural vessels was observed among groups, in contrast to what was found in a sciatic nerve crush model, in which exercise promoted increase in endoneural vessels (Kakihata et al., 2016).

A fast restoration of function seen in this study for both exercise intensities, as assessed on the eleventh postinjury day, corroborated with the results of a prior study that applied 5 weeks of training at an intensity of $9 \mathrm{~m} / \mathrm{min}$ for $60 \mathrm{~min}$ in a sciatic nerve crush model. In that study, an improvement in the nerve function index was observed after one week of training, in contrast to the sedentary group (Ilha et al., 2008). In this study, the intensity training of $17 \mathrm{~m} / \mathrm{min}$ accelerated the functional restoration but did not maintain it as the intensity of $10 \mathrm{~m} / \mathrm{min} \mathrm{did}$; these functional results are associated with the histomorphometric findings of the muscle fibres in the $17 \mathrm{~m} / \mathrm{min}$ group, which show that, over time, this protocol can be harmful in the recovery of muscle and nervous tissues and function.

A study (Boeltz et al., 2013) with an exercise protocol of $10 \mathrm{~m} /$ min, starting the training on the third day after the injury, was 
performed to verify functional restoration after the repair of sciatic neurotmesis with fibrin glue. They found that moderate exercise enhanced functional recovery, although, there was no complete functional recovery. In another study in a sciatic neurotmesis model (Cannoy et al., 2016), after an exercise protocol of $10 \mathrm{~m} / \mathrm{min}$ for $60 \mathrm{~min}$ in two diferente slopes $0^{\circ}$ and $20^{\circ}$. The second group presented worse results in functional recovery, despite showing improvement in motor axon regeneration.

Analysis of the nerve, the muscle and their function, similar to what was conducted in this study, was performed in a mouse model of neurotmesis followed by neurorrhaphy (Park and Höke, 2014). The exercise programme consisted of $60 \mathrm{~min}$ of continuous running at a speed of $10 \mathrm{~m} / \mathrm{min}$. The proposed protocol resulted in faster recovery of forelimb grip function, better regeneration of the median nerve at 3-5 $\mathrm{mm}$ distal to the neurorrhaphy and larger fibre size in the forearm flexor digitorum muscle.

Exercise protocols with velocities close to $17 \mathrm{~m} / \mathrm{min}$ were used in sciatic nerve crush models. In one study (Jang and Lee, 2015), the exercise performed at $5 \mathrm{~m} / \mathrm{min}$ during $20 \mathrm{~min}$ for the first week and at $15 \mathrm{~m} / \mathrm{min}$ during $60 \mathrm{~min}$ from the second to the fourth weeks, significantly increased functional recovery. In another study (Seo et al., 2006), the animals walked on a treadmill at a velocity of $18 \mathrm{~m} / \mathrm{min}$ for $30 \mathrm{~min}$. An improvement in axonal regeneration and function were observed in the exercised group compared with the sedentary. These results may be due to the protocols chosen; in the study of Jang and Lee (2015), the speed was slightly lower, while in the study of Seo et al. (2006) the daily exercise time of $60 \mathrm{~min}$ was divided into two sessions per day.

The intensity of the exercise was determined by exercise duration, slope and speed (Abreu et al., 2016; Marqueste et al., 2004). However, interval and continuous protocol training, with their different physiological adaptations (de Araujo et al., 2015), may have differential effects on the results and need to be considered. High-intensity interval exercise on treadmill was enough to promote axonal growth similar to that promoted by sixty minutes on a treadmill at $10 \mathrm{~m} / \mathrm{min}$ after fibular nerve transection in mice (Sabatier et al., 2008).

Thus, it is important to consider the variables that determine the intensity of treadmill exercise rehabilitation after nerve injury and to analyse which type of protocol is most appropriate for each situation. Perhaps longer protocols require moderation in speed, as seen at the suboptimal recovery of the $17 \mathrm{~m} / \mathrm{min}$ group and in the slope of the treadmill, as reported by Cannoy et al. (2016), however, higher speeds should not be discarded, since the duration of exercise can be adjusted. In addition, it is necessary to consider other specifics that may influence the results of an exercise protocol, such as modality (Bonetti et al., 2017), age (Cunha et al., 2011), gender (Acosta et al., 2017), and prior disease (Kim and Lee, 2010).

Exercise is a rehabilitation strategy is potentially favourable to nerve regeneration and functional restoration; protocols need to be investigated to maximize their effectiveness (English et al., 2011). This study evaluated the action of two exercise intensities on the regeneration of two median nerve segments, distal and proximal to the injury. Also, on the muscle and on the function restoration. The results confirmed that moderate exercise accentuates nerve regeneration, accelerates functional recovery and prevents muscle atrophy. The intensity of the exercise has a key role in the function restoration and in the muscular and nervous tissues recovery process, since an increase of $7 \mathrm{~m} / \mathrm{min}$ in velocity produces undesired results. Moderate exercises should be considered as a potential therapy to promote nerve regeneration and functional recovery after peripheral nerve injury.

\section{CONFLICT OF INTEREST}

No potential conflict of interest relevant to this article was reported.

\section{ACKNOWLEDGMENTS}

The authors thank FAPEMIG (Minas Gerais State Agency for Research and Development) for financial support and scholarships. The funders had no role in study design, data collection and analysis, decision to publish or preparation of the manuscript.

\section{REFERENCES}

Abreu P, Mendes SVD, Leal-Cardoso JH, Ceccatto VM. Anaerobic threshold employed on exercise training prescription and performance assessment for laboratory rodents: a short review. Life Sci 2016;151:1-6.

Acosta MC, Copley PA, Harrell JR, Wilhelm JC. Estrogen signaling is necessary for exercise-mediated enhancement of motoneuron participation in axon regeneration after peripheral nerve injury in mice. Dev Neurobiol 2017;77:1133-1143.

Armada-da-Silva PA, Pereira C, Amado S, Veloso AP. Role of physical exercise for improving posttraumatic nerve regeneration. Int Rev Neurobiol 2013;109:125-149.

Bertelli JA, Mira JC. The grasping test: a simple behavioral method for objective quantitative assessment of peripheral nerve regeneration in the rat. J Neurosci Methods 1995;58:151-155. 
Boeltz T, Ireland M, Mathis K, Nicolini J, Poplavski K, Rose SJ, Wilson E, English AW. Effects of treadmill training on functional recovery following peripheral nerve injury in rats. J Neurophysiol 2013;109:26452657.

Boerboom A, Dion V, Chariot A, Franzen R. Molecular mechanisms involved in Schwann cell plasticity. Front Mol Neurosci 2017;10:38.

Bonetti LV, Malysz T, Ilha J, Barbosa S, Achaval M, Faccioni-Heuser MC. The effects of two different exercise programs on the ultrastructural features of the sciatic nerve and soleus muscle after sciatic crush. Anat Rec (Hoboken) 2017;300:1654-1661.

Bontioti EN, Kanje M, Dahlin LB. Regeneration and functional recovery in the upper extremity of rats after various types of nerve injuries. J Peripher Nerv Syst 2003;8:159-168.

Cannoy J, Crowley S, Jarratt A, Werts KL, Osborne K, Park S, English AW. Upslope treadmill exercise enhances motor axon regeneration but not functional recovery following peripheral nerve injury. J Neurophysiol 2016;116:1408-1417.

Cobianchi S, Arbat-Plana A, Lopez-Alvarez VM, Navarro X. Neuroprotective effects of exercise treatments after injury: the dual role of neurotrophic factors. Curr Neuropharmacol 2017;15:495-518.

Coradini JG, Kunz RI, Kakihata CM, Errero TK, Bonfleur ML, Ribeiro Lde F, Brancalhão RM, Bertolini GR. Swimming does not alter nociception threshold in obese rats submitted to median nerve compression. Neurol Res 2015;37:1118-1124.

Cunha NB, Ilha J, Centenaro LA, Lovatel GA, Balbinot LF, Achaval M. The effects of treadmill training on young and mature rats after traumatic peripheral nerve lesion. Neurosci Lett 2011;501:15-19.

Daneyemez M, Solmaz I, Izci Y. Prognostic factors for the surgical management of peripheral nerve lesions. Tohoku J Exp Med 2005;205:269275.

de Araujo GG, Gobatto CA, Marcos-Pereira M, Dos Reis IG, Verlengia R. Interval versus continuous training with identical workload: physiological and aerobic capacity adaptations. Physiol Res 2015;64:209-219.

English AW, Wilhelm JC, Sabatier MJ. Enhancing recovery from peripheral nerve injury using treadmill training. Ann Anat 2011;193:354-361.

Faroni A, Mobasseri SA, Kingham PJ, Reid AJ. Peripheral nerve regeneration: experimental strategies and future perspectives. Adv Drug Deliv Rev 2015;82-83:160-167.

Faturi FM, Franco RC, Gigo-Benato D, Turi AC, Silva-Couto MA, Messa

SP, Russo TL. Intermittent stretching induces fibrosis in denervated rat muscle. Muscle Nerve 2016;53:118-126.

Geuna S, Raimondo S, Fregnan F, Haastert-Talini K, Grothe C. In vitro models for peripheral nerve regeneration. Eur J Neurosci 2016;43:287296.

Gigo-Benato D, Russo TL, Tanaka EH, Assis L, Salvini TF, Parizotto NA.
Effects of 660 and $780 \mathrm{~nm}$ low-level laser therapy on neuromuscular recovery after crush injury in rat sciatic nerve. Lasers Surg Med 2010; 42:673-682.

Gordon T, Borschel GH. The use of the rat as a model for studying peripheral nerve regeneration and sprouting after complete and partial nerve injuries. Exp Neurol 2017;287(Pt 3):331-347.

Gordon T, English AW. Strategies to promote peripheral nerve regeneration: electrical stimulation and/or exercise. Eur J Neurosci 2016;43:336350.

Gutrecht JA, Dyck PJ. Quantitative teased-fiber and histologic studies of human sural nerve during postnatal development. J Comp Neurol 1970;138:117-129.

Ilha J, Araujo RT, Malysz T, Hermel EE, Rigon P, Xavier LL, Achaval M. Endurance and resistance exercise training programs elicit specific effects on sciatic nerve regeneration after experimental traumatic lesion in rats. Neurorehabil Neural Repair 2008;22:355-366.

Jang SH, Lee JH. Effects of physical exercise on the functional recovery of rat hindlimbs with impairments of the sciatic nerve as assessed by $2 \mathrm{D}$ video analysis. J Phys Ther Sci 2015;27:935-938.

Kakihata CM, Malanotte JA, Karvat J, Brancalhão RM, de Fátima Chasko Ribeiro L, Bertolini GR. The morphological and functional effects of exercise in the aquatic environment, performed before and/or after sciatic nerve compression in Wistar rats. J Exerc Rehabil 2016;12:393400.

Kim WS, Lee SU. Harmful effect of land-based endurance exercise in rats with diabetic nerve. Med Sci Sports Exerc 2010;42:1625-1631.

Kouyoumdjian JA, Graça CR, Ferreira VFM. Peripheral nerve injuries: a retrospective survey of 1124 cases. Neurol India 2017;65:551-555.

Lansford KA, Shill DD, Dicks AB, Marshburn MP, Southern WM, Jenkins NT. Effect of acute exercise on circulating angiogenic cell and microparticle populations. Exp Physiol 2016;101:155-167.

Marqueste T, Alliez JR, Alluin O, Jammes Y, Decherchi P. Neuromuscular rehabilitation by treadmill running or electrical stimulation after peripheral nerve injury and repair. J Appl Physiol (1985) 2004;96:19881995.

Miranda GE, Torres RY. Epidemiology of traumatic peripheral nerve injuries evaluated with electrodiagnostic studies in a tertiary care hospital clinic. P R Health Sci J 2016;35:76-80.

Panagopoulos GN, Megaloikonomos PD, Mavrogenis AF. The Present and future for peripheral nerve regeneration. Orthopedics 2017;40: e141-156.

Papalia I, Magaudda L, Righi M, Ronchi G, Viano N, Geuna S, Colonna MR. Epineurial window is more efficient in attracting axons than simple coaptation in a sutureless (Cyanoacrylate-Bound) model of end-toside nerve repair in the rat upper limb: functional and morphometric 
evidences and review of the literature. PLoS One 2016;11:e0148443.

Papalia I, Tos P, Stagno d'Alcontres F, Battiston B, Geuna S. On the use of the grasping test in the rat median nerve model: a re-appraisal of its efficacy for quantitative assessment of motor function recovery. J Neurosci Methods 2003;127:43-47.

Park JS, Höke A. Treadmill exercise induced functional recovery after peripheral nerve repair is associated with increased levels of neurotrophic factors. PLoS One 2014;9:e90245.

Ronchi G, Nicolino S, Raimondo S, Tos P, Battiston B, Papalia I, Varejão AS, Giacobini-Robecchi MG, Perroteau I, Geuna S. Functional and morphological assessment of a standardized crush injury of the rat median nerve. J Neurosci Methods 2009;179:51-57.

Rushton WA. A theory of the effects of fibre size in medullated nerve. J Physiol 1951;115:101-122.

Russo TL, Peviani SM, Durigan JL, Salvini TF. Electrical stimulation increases matrix metalloproteinase-2 gene expression but does not change its activity in denervated rat muscle. Muscle Nerve 2008;37:593-600.

Sabatier MJ, Redmon N, Schwartz G, English AW. Treadmill training promotes axon regeneration in injured peripheral nerves. Exp Neurol 2008;211:489-493.

Santos AP, Suaid CA, Fazan VP, Barreira AA. Microscopic anatomy of brachial plexus branches in Wistar rats. Anat Rec (Hoboken) 2007;290: $477-485$.

Santos AP, Suaid CA, Xavier M, Yamane F. Functional and morphometric differences between the early and delayed use of phototherapy in crushed median nerves of rats. Lasers Med Sci 2012;27:479-486.
Seo TB, Han IS, Yoon JH, Hong KE, Yoon SJ, Namgung U. Involvement of $\mathrm{Cdc} 2$ in axonal regeneration enhanced by exercise training in rats. Med Sci Sports Exerc 2006;38:1267-1276.

Sulaiman W, Gordon T. Neurobiology of peripheral nerve injury, regeneration, and functional recovery: from bench top research to bedside application. Ochsner J 2013;13:100-108.

Sullivan R, Dailey T, Duncan K, Abel N, Borlongan CV. Peripheral nerve injury: stem cell therapy and peripheral nerve transfer. Int J Mol Sci 2016;17(12). pii: E2101.

Szyłejko A, Bielecki M, Terlikowski R. Epidemiology of upper limb peripheral nerve injuries in the material collected in the Department of Orthopedics and Traumatology Medical University of Bialystok. Prog Heal Sci Orthop Bialystok. Prog Heal Sci 2015;5:130-137.

Taylor CA, Braza D, Rice JB, Dillingham T. The incidence of peripheral nerve injury in extremity trauma. Am J Phys Med Rehabil 2008;87:381385.

Terra R, Silva SA, Pinto VS, Dutra PM. Effect of exercise on the immune system: response, adaptation and cell signaling. Rev Bras Med Esporte 2012;18:208-214.

Udina E, Cobianchi S, Allodi I, Navarro X. Effects of activity-dependent strategies on regeneration and plasticity after peripheral nerve injuries. Ann Anat 2011a;193:347-353.

Udina E, Puigdemasa A, Navarro X. Passive and active exercise improve regeneration and muscle reinnervation after peripheral nerve injury in the rat. Muscle Nerve 2011b;43:500-509. 